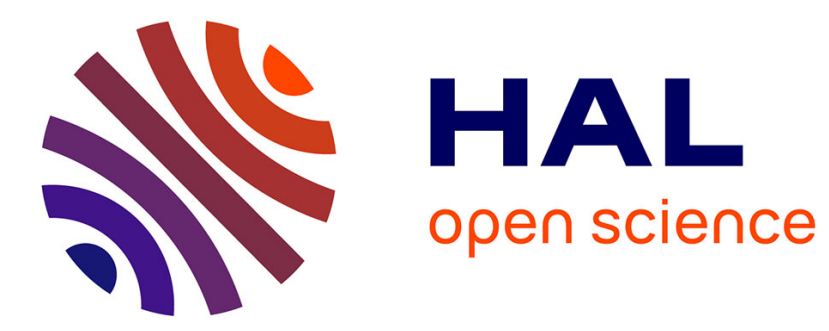

\title{
Control of mass and heat transfer for steel/aluminium joining using Cold Metal Transfer process
}

\author{
Bachir Mezrag, Frédéric Deschaux-Beaume, Mustapha Benachour
}

\section{To cite this version:}

Bachir Mezrag, Frédéric Deschaux-Beaume, Mustapha Benachour. Control of mass and heat transfer for steel/aluminium joining using Cold Metal Transfer process. Science and Technology of Welding and Joining, 2015, 20 (3), pp.189-198. 10.1179/1362171814Y.0000000271 . hal-01289341

\section{HAL Id: hal-01289341 https://hal.science/hal-01289341}

Submitted on 16 Mar 2016

HAL is a multi-disciplinary open access archive for the deposit and dissemination of scientific research documents, whether they are published or not. The documents may come from teaching and research institutions in France or abroad, or from public or private research centers.
L'archive ouverte pluridisciplinaire $\mathbf{H A L}$, est destinée au dépôt et à la diffusion de documents scientifiques de niveau recherche, publiés ou non, émanant des établissements d'enseignement et de recherche français ou étrangers, des laboratoires publics ou privés. 


\title{
Control of mass and heat transfer for steel/ aluminium joining using Cold Metal Transfer process
}

\section{B. Mezrag ${ }^{1,2}$, F. Deschaux-Beaume ${ }^{1 *}$ and M. Benachour ${ }^{2}$}

\begin{abstract}
The Cold Metal Transfer process is investigated to join zinc coated steel with aluminium alloy by braze-welding. A 4043 filler metal is deposited on the surface of the coated steel, and the effect of the current waveform on the metal transfer and the heat transferred to the base metal is investigated. The reduction in the 'boost phase' duration of the current waveform decreases the volume of liquid drops at the wire tip and allows to increase the short-circuit frequency, inducing a similar or higher deposit rate. Regular deposits are obtained when the linear energy remains below $\sim 500 \mathrm{~J} \mathrm{~mm}^{-1}$. The heat transferred to the base metal, and thus the thickness of the intermetallic layer formed at the $\mathrm{Al} /$ steel interface, is lower for an equivalent deposit rate when the short-circuit frequency is high.
\end{abstract}

Keywords: Gas metal arc welding, Cold metal transfer, Aluminium-steel joining, Metal transfer, Heat transfer, Intermetallic

\section{Introduction}

Steel and aluminium are commonly joined by mechanical means like screwing, riveting or clinching, but also with solid state welding processes like explosion welding, ${ }^{1}$ friction welding, ${ }^{2}$ or more recently by friction stir welding. ${ }^{3}$ In contrast, steel to aluminium fusion welding remains a technological issue due to the great difference in physical properties of both materials (melting temperature, coefficient of thermal expansion...) and most of all because of the near zero solid solubility of iron in aluminium, which involves the creation of brittle intermetallic phases. Despite the difficulties of assembling steel to aluminium by liquid state processes, several studies have been carried out using conventional processes such as arc welding, ${ }^{4,5}$ resistance spot welding, 6,7 brazing, ${ }^{8,9}$ or laser welding. ${ }^{10,11}$ The reactive-wetting or braze-welding technique in a lap-welding configuration specially gives promising results. ${ }^{12-14}$ It consists in melting aluminium base metal or a low melting point aluminium filler metal, producing its spreading on the solid steel base metal. However, if the wetting of liquid aluminium is possible on zinc coated steels, it requires the use of a brazing flux on non coated steels. ${ }^{12,13}$ The quality of the bonds then greatly depends on the thickness of $\mathrm{Fe}-\mathrm{Al}$ intermetallic phases formed at the interface between steel to aluminium. Good mechanical properties can be achieved when the thickness of this intermetallic layer is $<10 \mu \mathrm{m} .{ }^{13}$ The thickness of the intermetallic layer can be reduced by the

${ }^{1}$ Mechanical and Civil Engineering Laboratory, University Montpellier II, 30907 Nîmes, France

${ }^{2}$ Ingeniery of Mechanical Systems and Materials Laboratory, University of Tlemcen, 13000, Tlemcen, Algeria

Corresponding author: Pr Frédéric Deschaux-Beaume; email: deschaux@ iut-nimes.fr addition of $\mathrm{Si}$ on the $\mathrm{Al}$ alloy. ${ }^{14,15}$ It is generally accepted that the growth kinetic of intermetallics is mainly controlled by the diffusion thought the intermetallic layer. ${ }^{12}$ This phenomenon depends on temperature of the steel-aluminium interface, that has to be reduced to prevent an excessive growth. During the past few years, new controlled short-circuit Gas Metal Arc Welding processes (GMAW), allowing the melting of filler metals with low heat input, have been developed. The Cold Metal Transfer process (CMT) developed by Fronius seems to be the more promising. Due to a fine control of current waveform coupled to an alternate feeding of the filler wire, the metal transfer is possible with a very low heat input, promoting the welding of thin sheets with low distortion and gap bridging ability. ${ }^{16}$ This process has been tested to join aluminium to zinc coated steel by braze-welding in a lap joint with Al-Si filler wires. ${ }^{17-20}$ The formed intermetallic layer is $<10 \mu \mathrm{ms}$ if the heat input remains low. ${ }^{17,19,20}$ It has been observed that the $\mathrm{Zn}$ coating plays an important role by promoting the wetting of aluminium, but also by preventing the formation of a thick intermetallic layer. ${ }^{21}$ However, a too high heat input can promote the vapourisation of the $\mathrm{Zn}$ coating, producing a detrimental effect on the steel-aluminium bond.

The complex waveform of the welding current in the CMT process and the 'back feeding' of the filler wire that mechanically forces the metal transfer make difficult to understand the relation between welding parameters, metal transfer and heat transfer. Pickin et al. investigated the effect of the CMT process on the dilution during aluminium alloy welding, compared to a pulsed GMAW process, and concluded the dilution is lower with CMT, for the same filler wire speed. ${ }^{22}$ However, the effect of the various parameters of the CMT current waveform on the heat and metal transfers has never been discussed. 
In this paper, we investigate the effect of various current waveforms of the CMT process on the characteristics of transfer and deposit of a Al-Si filler wire on $\mathrm{Zn}$ coated steel samples. The relations between waveform parameters, energy, melting rate of the filler wire, wetting of the deposited metal, and thickness of intermetallic layer are discussed.

\section{Experimental details}

During lap braze-welding of aluminium alloy with a $\mathrm{Zn}$ coated steel using an aluminium alloy filler metal, the main issue concerns the interaction of molten aluminium alloy with steel, generally remained in a solid state. This high temperature interaction promotes the forming and growth of brittle $\mathrm{Fe}-\mathrm{Al}$ intermetallic compounds. In order to study the effect of welding parameters on the characteristics of the joining interface, weld deposits of Al alloy filler metal are achieved on $\mathrm{Zn}$ coated steel samples.

\section{Welding conditions}

Weld deposit of a 4043 (A1Si5) aluminium alloy filler wire (Table 1) of $1.2 \mathrm{~mm}$ diameter is achieved on samples of base metal of $60 \times 150 \mathrm{~mm}^{2}$. The base material is a zinc coated S235 steel sheet of $1 \mathrm{~mm}$ thick.

A TransPuls Synergic 2700 CMT power source is used in this study. The GMAW-CMT process allows welding under low heat input with a controlled short-circuit metal transfer, thanks to a complex current waveform coupled to the alternate feeding of the filler wire. A typical electrical cycle obtained with this process is given in Fig. $1 a$. The voltage is controlled by the arc length, depending on the filler wire moving. The current waveform is characterised mainly by the 'boost' current $\mathrm{I}_{\mathrm{b}}$, the duration of the pulse $t_{b}$, the 'wait' current $I_{w}$, and the short-circuit current $I_{\mathrm{sc}}$. Seventeen set of parameters were chosen for this study (Table 2). The filler wire speed $V_{f}$ (feed and retreat) is the same for every test, as well as the short-circuit current. The boost current and the wait current are different for each test, as well as the pulse time. As the durations of the wait current and the shortcircuit do not change drastically (they are governed by the alternate moving of the filler wire), the change in pulse time also changes the frequency of the short-circuits.

The shielding gas is a commercial argon with purity higher than 99.99\% (Argon Technique, Air Products), with a flow of $121 \mathrm{~min}^{-1}$. The welding speed is the same for all the tests, equal to $60 \mathrm{~cm} \mathrm{~min}^{-1}$.

\section{Instrumentation of the welding process}

The electrical parameters as well as the welding speed are recorded during the whole welding test with a frequency of $80 \mathrm{kHz}$. The welding current is measured with a Hall effect based current transducers (LEM LT 505-S), and the voltage is measured between the steel sample and the contact tip of the welding gun. In order to observe in situ the melting of the filler wire and the metal transfer, video recordings of the filler wire tip are made with a high speed camera (Phantom ir300) at 5000 images per second. To partly eliminate the arc radiation, a $808 \mathrm{~nm}$ interferential filter is placed on the camera, and coupled to a laser diode to light the tip of the filler wire.

The CMT process is characterised by an alternate movement of the filler wire. To control the wire speed, a DV 25 ST wire feed sensor is connected to the welding torch. In addition, the measure of wire feedrate by image correlation is made on some high speed video recordings using Phantom PCC $2 \cdot 14 \mathrm{~b}$ software to calibrate and validate the measurements of the wire feed sensor. Image analyses on high speed video recordings are also performed using ImageJ software to measure geometrical characteristics of the filler wire tip.

\section{Characterisation methods}

After each weld deposit, the total weight of deposited metal is measured using a Ohaus Explorer balance with a precision of $10^{-4} \mathrm{~g}$. The mean width of the deposits is measured by image analysis on top views using a Leica Z16 APO macroscope with the Leica LAS software. In addition three cross-sections are cut on each sample by water jet cutting, to measure geometrical characteristics of the deposit (width, height). Finally, cross-sections were polished and finished with a 1 micrometre diamond suspension, in order to clearly observe the intermetallic layer formed at the interface between the steel and the aluminium weld deposit. The thickness of the intermetallic is measured using a Leica DMI5000 M optical microscope and the LAS software.

\section{Results}

\section{Analysis of the CMT transfer cycle}

The high speed videos coupled to electrical and wire speed measures first allow to analyse the various phases of the CMT process and the regularity of the metal transfer. Fig. 1 shows an example of transfer cycle, with the evolution of the current, voltage and wire speed measured during a test, and images corresponding to various steps of the metal transfer.

Table 2 Welding parameters for the various tests

\begin{tabular}{llllll}
\hline Test $\mathbf{N}^{\circ}$ & $I_{b}(A)$ & $t_{b}(\mathbf{m s})$ & $I_{w}(A)$ & $I_{s c}(A)$ & $V_{f}\left(\mathbf{m ~ m i n}^{-1}\right)$ \\
\hline 1 & 24 & 29 & 15 & 40 & 20 \\
2 & 27 & 22 & 15 & 40 & 20 \\
3 & 30 & 15 & 15 & 40 & 20 \\
4 & $47 \cdot 1$ & $13 \cdot 01$ & $16 \cdot 4$ & 40 & 20 \\
5 & $64 \cdot 3$ & $11 \cdot 01$ & $17 \cdot 8$ & 40 & 20 \\
6 & $81 \cdot 4$ & $9 \cdot 01$ & $19 \cdot 2$ & 40 & 20 \\
7 & $98 \cdot 5$ & $7 \cdot 01$ & $20 \cdot 7$ & 40 & 20 \\
8 & $115 \cdot 7$ & $5 \cdot 01$ & $22 \cdot 1$ & 40 & 20 \\
9 & $132 \cdot 8$ & $3 \cdot 01$ & $23 \cdot 5$ & 40 & 20 \\
10 & 150 & 1 & 25 & 40 & 20 \\
11 & 150 & $1 \cdot 15$ & $28 \cdot 8$ & 40 & 20 \\
12 & 150 & $1 \cdot 30$ & $32 \cdot 6$ & 40 & 20 \\
13 & 150 & $1 \cdot 38$ & $34 \cdot 6$ & 40 & 20 \\
14 & 150 & $1 \cdot 53$ & $38 \cdot 4$ & 40 & 20 \\
15 & 150 & $1 \cdot 61$ & $40 \cdot 3$ & 40 & 20 \\
16 & 150 & $1 \cdot 69$ & $42 \cdot 3$ & 40 & 20 \\
17 & 150 & $1 \cdot 76$ & $44 \cdot 2$ & 40 & 20 \\
\hline
\end{tabular}

Table 1 Composition of the 4043 (AISi5) filler wire

\begin{tabular}{lllllllll}
\hline Element & Si & Mn & Mg & Cu & Fe & Zn & Ti & \\
\hline Weight $-\%$ & 5 & $<0,05$ & $<0,05$ & $<0,05$ & $<0,40$ & $<0,10$ & $<0,20$ & Solde \\
\hline
\end{tabular}



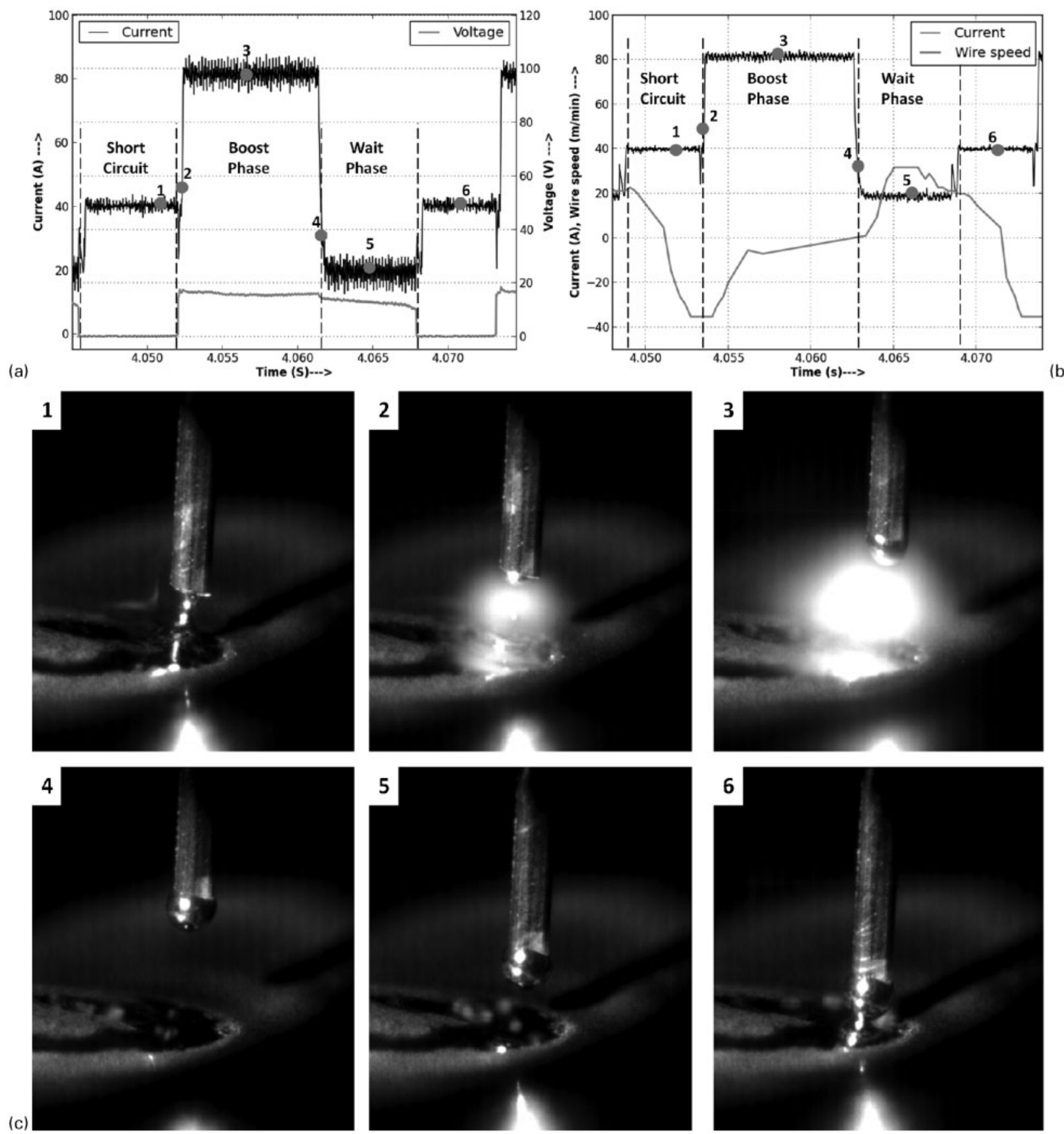

1 example of CMT electrical and wire speed cycle (a-b) and corresponding high speed video recording (c)

The boost current begins just at the end of the short circuit phase, and allows the restriking of the electrical arc (image 2 of Fig. 1c). During all the boost phase, the wire stays in static position (the wire feedrate is about zero) and a liquid drop is formed at the wire tip (image 3). After this first phase, at the beginning of the wait phase, the current decreases drastically to avoid the growth and the detachment of the drop, and the filler wire rate increases up to a rather constant value, before decreasing again when the short-circuit phase, characterised by a near zero voltage, begins (images 4 to 6). Note that the maximum wire speed measured with wire feed sensor and image analysis $\left(32 \mathrm{~m} \mathrm{~min}^{-1}\right)$ is higher than the fixed value $\left(20 \mathrm{~m} \mathrm{~min}^{-1}\right)$. The wire feed speed then becomes negative, indicating the retreat of the wire during the end of the short-circuit phase at a constant speed slightly higher $\left(34 \mathrm{~m} \mathrm{~min}^{-1}\right)$ than the feed speed of the wait phase. During the short-circuit phase, the current is at a constant value of $40 \mathrm{~A}$. Note that the arc voltage is constant during the boost phase, but continuously decreases during the wait phase due to the decrease in the arc length.

\section{Evolution of waveform parameters and power for the various tests}

Figure 2 shows the evolution of the current of the three phases of the CMT cycle measured during the various tests. These values correspond to the mean currents numerically computed from the recordings performed during the total welding time. The current values measured are rather close to the setpoint values (Table 1), indicating a good current control of the CMT process. One can see the boost current increases slowly on the three first tests, then faster up to the 10th test and finally remains constant 


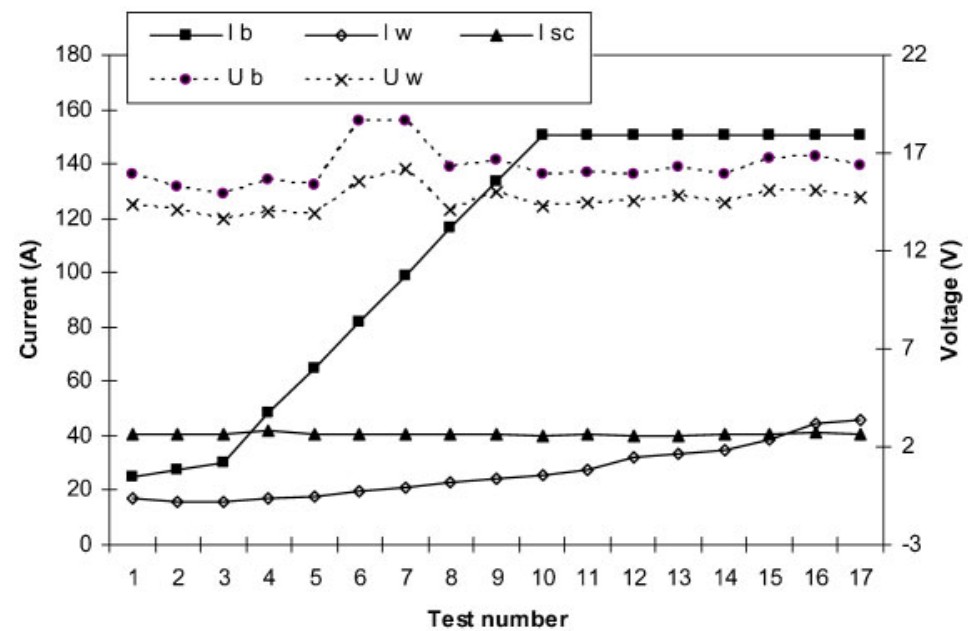

2 evolution of the mean current and voltage of the three phases of the CMT cycle for the various tests

at $\sim 150 \mathrm{~A}$. The wait current decreases slightly on the three first tests (while the setpoint values are constant), and then continuously increases. The short circuit current remains at a constant value of $\sim 40 \mathrm{~A}$ on all the tests, corresponding to the setpoint value.

The boost time is fixed as a setpoint in the CMT welding programme (Table 1). Measurements indicate the setpoint values are well followed (Fig. 3). At the opposite, the wait time and short-circuit time are not fixed as setpoints. The wait phase duration is controlled by the time required for the filler wire tip to touch the base metal surface from the distance corresponding to the arc length of the boost phase, and the duration of the short circuit phase by the time required to 'detach' the liquid metal drop under the effect of the wire retreat at constant speed. As the wire speed is constant on all the tests, the duration of the wait and short circuit phases depend on the drop volume and geometry. A large drop for instance will tend to increase the short circuit duration. Figure 3 shows the wait and short-circuit times are rather constant at $\sim 5 \mathrm{~ms}$ except on tests 5 to 8 , and specially on test $n^{\circ} 7$ where it is higher than $6 \mathrm{~ms}$. It is probably due to a higher drop volume that increases the short-circuit duration, and then the phase of wire retreat, producing a higher arc length during the boost phase (confirmed by a higher voltage shown in Fig. 2), and then a longer wait phase during which the wire is feeded to reach the short-circuit.

As a consequence of the decrease in the boost time, the frequency of the short-circuits, calculated by Fourier transformation of the voltage signal, increases up to test $\mathrm{n}^{\circ} 10$, and then remains rather constant (Fig. 3). Note that the arcing time $\left(t_{b}\right.$ plus $\left.t_{w}\right)$ is higher than the shortcircuit time on the first tests, whereas the arcing and short-circuit times are quite similar from test $n^{\circ} 10$.

Figure 4 shows the evolution of the mean welding power. The mean values are numerically computed by time integration of the instantaneous electrical power on the total welding period $(10 \mathrm{~s})$ :

$$
P=\frac{1}{t_{\mathrm{f}}} \int_{\mathrm{t}=0}^{\mathrm{tf}} \mathrm{UIdt}
$$

where $\mathrm{U}$ and I are respectively the instantaneous voltage and current measured, and $t_{\mathrm{f}}$ the total welding period.

The mean power varies from $320 \mathrm{~W}$ to $790 \mathrm{~W}$. Note that during the short-circuit phase, the instantaneous power becomes very low (the voltage is near zero). To compare the arcing phase of the various tests, we also have computed the mean arc power. The differences between the various tests are greater for the mean arc

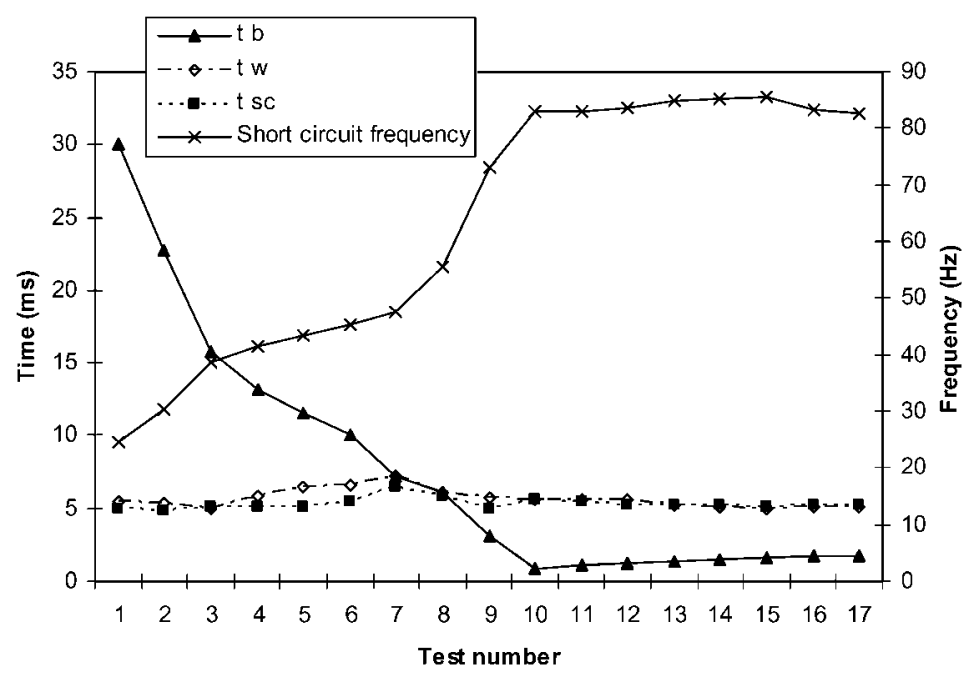

3 evolution of the duration of the three phases of the CMT cycle and of the short-circuit frequency for the various tests 


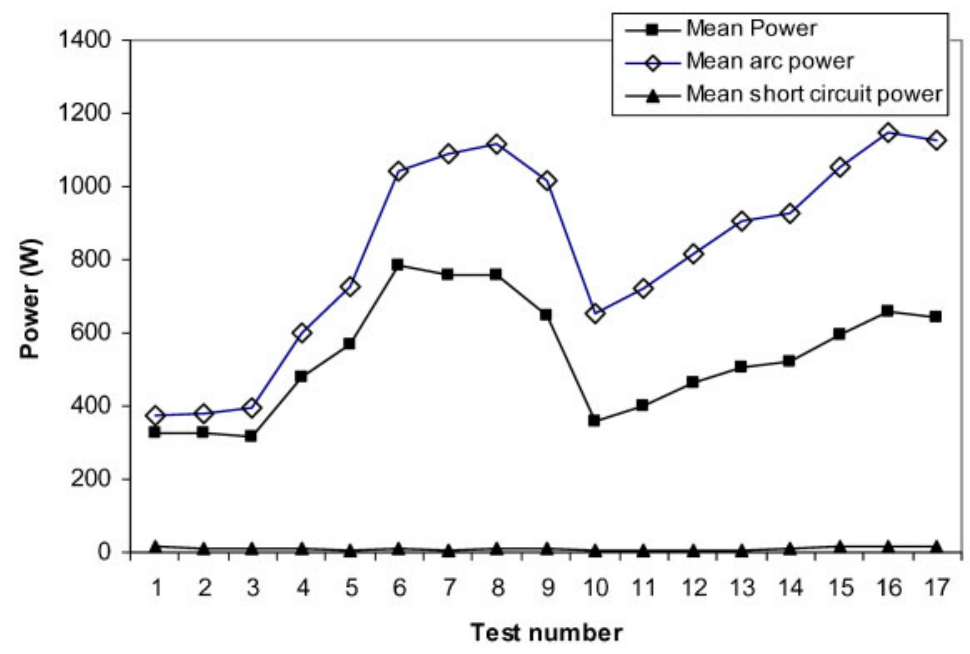

4 mean power for the various tests

power, from $\sim 370 \mathrm{~W}$ to $1150 \mathrm{~W}$. Note that the mean power increases up to test $\mathrm{n}^{\circ} 6$ mainly due to the increase in the boost current, but decreases after, the effect of the decrease in boost time being more important than the effect of the increase in boost current. After test $n^{\circ} 10$, the power increases again due to the combined effect of a slight increase in the wait current and boost duration.

In welding, the energy transmitted to the base metal is generally expressed by the linear energy corresponding to the power divided by the welding speed (UI/V, in $\mathbf{J}$ $\mathrm{mm}^{-1}$ ). The total linear energy has been decomposed in three contributions corresponding to the boost, wait and short-circuit phases. Figure 5 shows the evolution of these parameters on the various tests. As the welding speed is constant on all the tests, the tendency for the total linear energy is the same as the mean power. One can observe the boost energy is the main contribution to the total energy on tests 1 to 9 , whereas the wait energy turns to the same order of magnitude on tests 10 to 17 , because the boost time is very short.

\section{Metal transfer}

The weight of deposited metal, measured with a precision balance, is shown in Figure 6. The deposited weight per second increases up to test $n^{\circ} 7$, then stabilises and decreases at test $\mathrm{n}^{\circ} 10$, before increasing again. These tendencies are globally similar to the power evolution (Fig. 4). However, one can see the deposit rate is higher for the last tests, where the short-circuit frequency is high, than for tests 6 to 8 , in spite of a higher power in this last case.

The deposited weight for each short-circuit is deduced using the short-circuit frequency computed in the previous section. In addition, the evolution of the surface drops at the wire tip is measured for some tests on high speed video by image analysis. An estimated deposited weight per short circuit is then computed, considering an axisymetric drop geometry. Some variations are observed considering a series of drop of one welding test, due to the non axisymetric real geometry of the drops, but the tendencies observed by direct weight measurements are well restituted, except for tests 5 to 7 where the calculation overestimates the measured weight (Fig. 7). Image analysis can thus be used to follow the evolution of the drops weight at the wire tip during the CMT cycle.

At the end of the short-circuit phase, when the arc restrikes, a weight of molten metal of $\sim 2 \mathrm{mg}$ remains attached to the wire tip, whatever the welding parameters (Fig. 8). The drops grow during the boost phase,

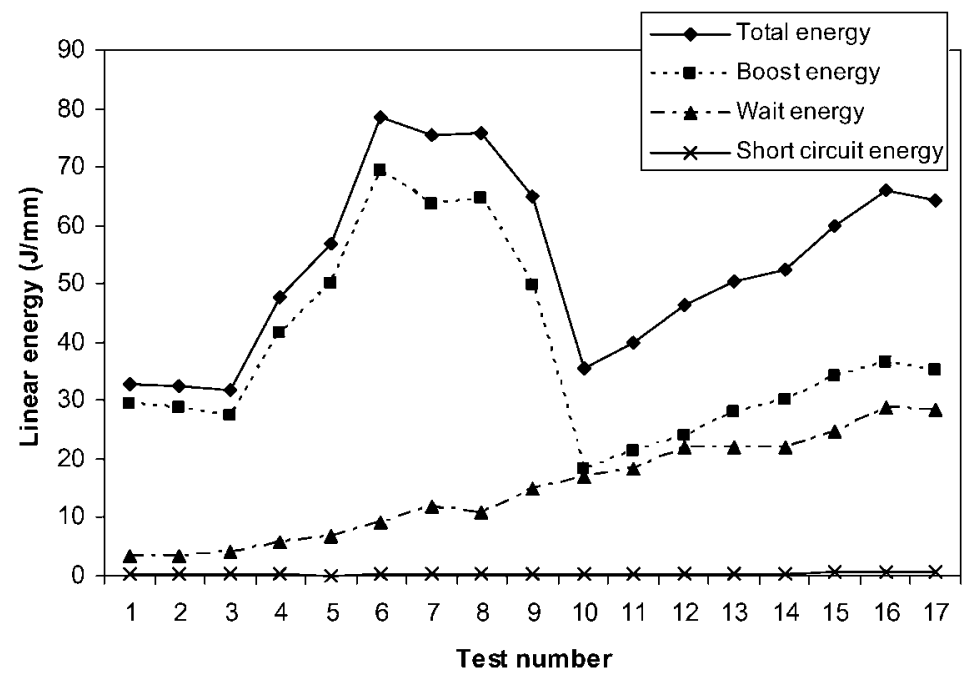

5 evolution of the linear energy for the various tests 


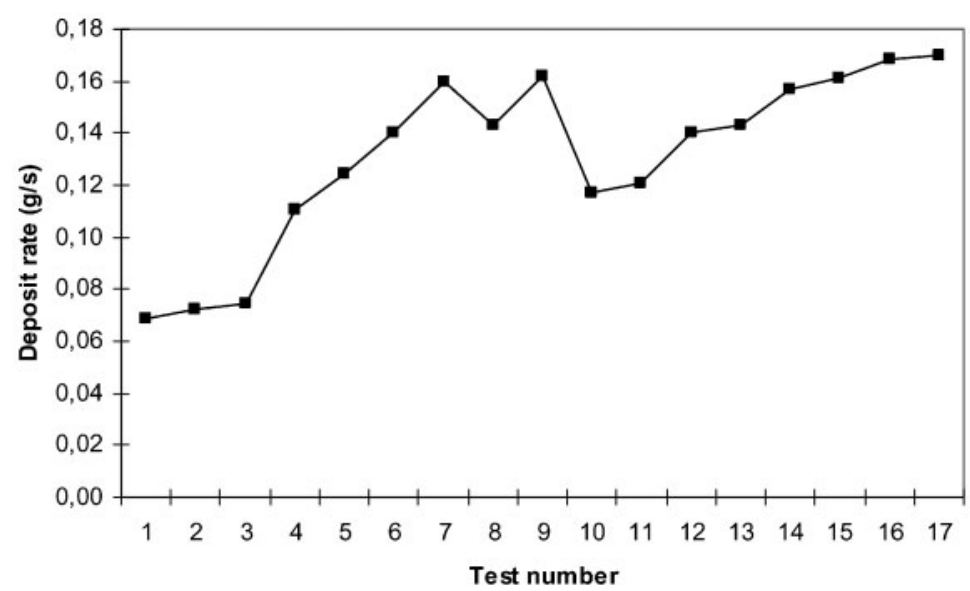

6 evolution of the deposit rate for the various tests

and continue to grow during the wait phase. One can deduce from Fig. 8 the main heat input producing the drop growth comes from the boost phase, but the wait phase contributes also significantly to the melting, the molten weight during this phase may represent $\sim 30 \%$ of the deposited weight for some welding conditions. The weight of each deposited drop is globally higher for the first tests than for the last ones from $n^{\circ} 10$, where the boost phase time is only $\sim 1 \mathrm{~ms}$. However, due to the high short-circuit frequency, the deposit rate is as high for the last tests than for the first ones (Fig. 6).

\section{Wetting of weld deposit and intermetallic thickness}

The wetting of aluminium on zinc coated steel is a main point to guaranty a good mechanical strength of the assembly, because the width of the joining interface depends on this phenomenon.

A good and regular wetting is observed when the linear energy remains below $\sim 500 \mathrm{~J} \mathrm{~mm}^{-1}$. For an energy range between 530 and $650 \mathrm{~J} \mathrm{~mm}^{-1}$, the deposit becomes less regular (Figs. 9-10). This could be due to the local vapourisation of the $\mathrm{Zn}$ layer, that prevents the wetting of liquid aluminium. Indeed, the direct wetting of liquid aluminium on uncoated steel is very poor compared to $\mathrm{Zn}$ coated steel. ${ }^{21}$ For regular deposits (deposits 1 to 4 and 10 to 13), the width of the deposit is comprised between $4.7 \mathrm{~mm}$ and $7 \cdot 8 \mathrm{~mm}$, and globally increases with energy. Note that for an equivalent energy, the width of deposits 10 to 13 is higher than the width of deposits 1 to 4 .

The thickness of the formed intermetallic layer is also a main point, because it determines the brittleness of the bond. It is generally admitted that due to kinetics considerations, the intermetallic formed at the $\mathrm{Fe} / \mathrm{Al}$ interface is mainly $\mathrm{Fe}_{2} \mathrm{Al}_{5},{ }^{14}$ while $\mathrm{FeAl}_{3}$ can sometimes also be observed on the aluminium side (Fig. 11). When the aluminium alloy contains silicon, the formed $\mathrm{Fe}_{2} \mathrm{Al}_{5}$ intermetallic generally contains a few per cent of $\mathrm{Si}$, that decreases the growth kinetics of the intermetallic layer by reducing the diffusion rate of $\mathrm{Fe}$ and $\mathrm{Al}$ through $\mathrm{Fe}_{2} \mathrm{Al}_{5} \cdot{ }^{14}$ It has been shown in previous studies that intermetallic thicknesses higher than $10 \mu \mathrm{ms}$ were generally cracked. ${ }^{13}$ For all the weld deposits, the maximum intermetallic thickness is $<8 \mu \mathrm{ms}$, due to the low heat input associated to the CMT process. However, the intermetallic thickness can change significantly according to the waveform characteristics. In order to investigate the influence of the current waveform on the intermetallic growth, four welding conditions are compared on Fig. 12, corresponding to two different waveform types giving rather equivalent deposit rates and widths: waveforms having an arcing duration higher than short-circuit time (tests 4 5), and equivalent arcing and short-circuit durations (tests 10-11). One can observe on Fig. 12 that for the last waveform type, the intermetallic thickness is globally

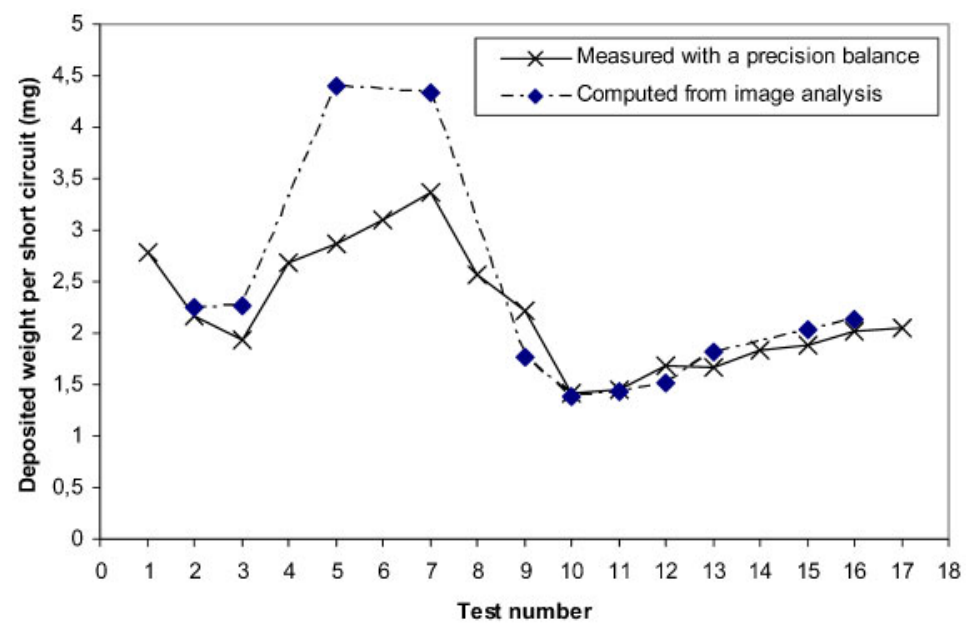

7 comparison of the drops weight measured with balance and computed from image analysis 


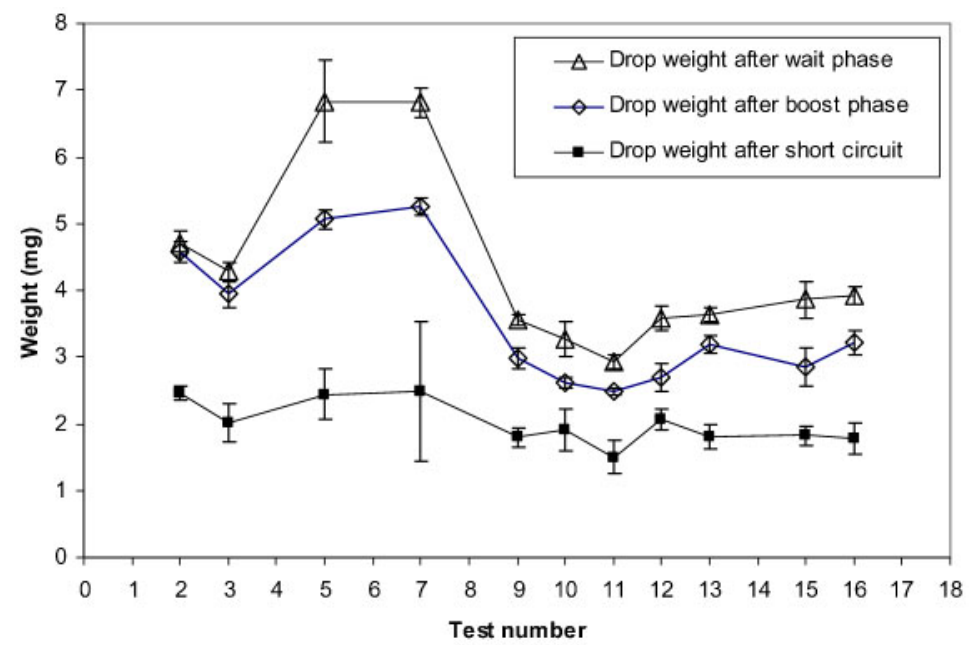

8 evolution of the drops weight computed from image analysis

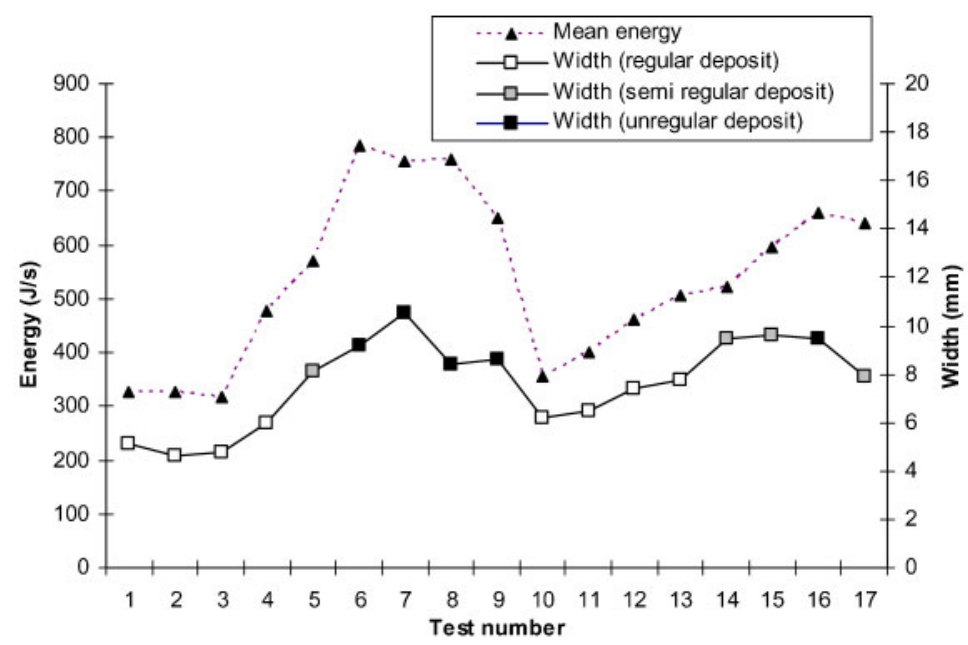

9 relation between energy, width and regularity of the various deposits

lower. This have to be correlated to the associated energy, which is higher for the first type of waveform, in spite of similar deposit rates.

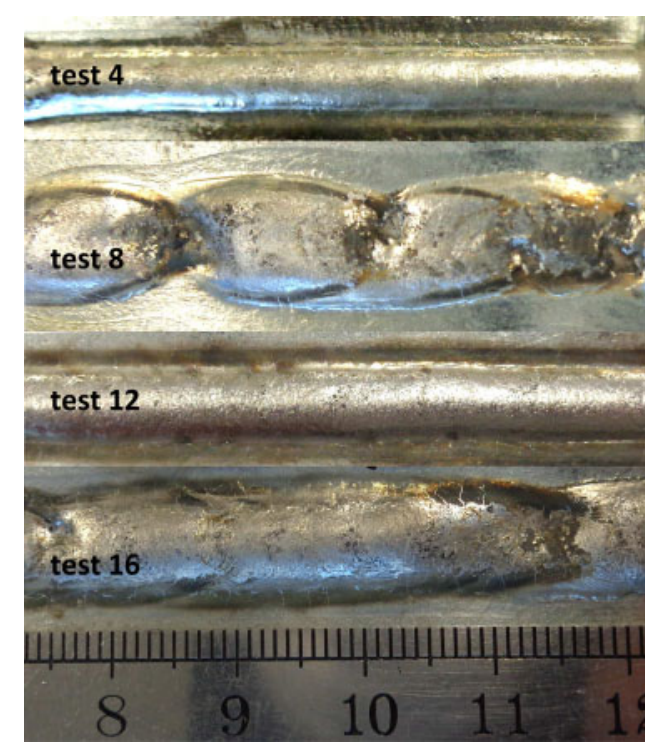

10 general aspect of the deposits

\section{Discussion}

In GMAW process, it is generally admitted, after the demonstration of Lesnewich, ${ }^{24}$ that the melting rate of the filler wire in direct current electrode positive (DCEP) is controlled by the combination of joule effect and condensation heat of electrons. The melting rate then increases with the welding current, generally following a polynomial law. However, has explained by Waszink, ${ }^{25}$ the melting of the filler wire tip results of heat inputs, but also of heat transfer, specially from the drop surface to the solid part of the wire.

If we consider the evolution of the deposit rate with the mean current for our tests, one can see there is no clear relation (Fig. 13). One can correlate these results to the special metal transfer mechanism related to the CMT process. During the short-circuit phase, the condensation heat of electrons does not occur, and heat transfer from the liquid drop to the base metal reduces the heat transferred to the solid filler wire, and then its melting rate. The heating of the wire tip during the arcing phase by joule effect and condensation heat of electrons is then partially balanced by the heat transfer in the base metal during the short-circuit phase. The contribution of both phenomena to the melting rate seems to vary according 


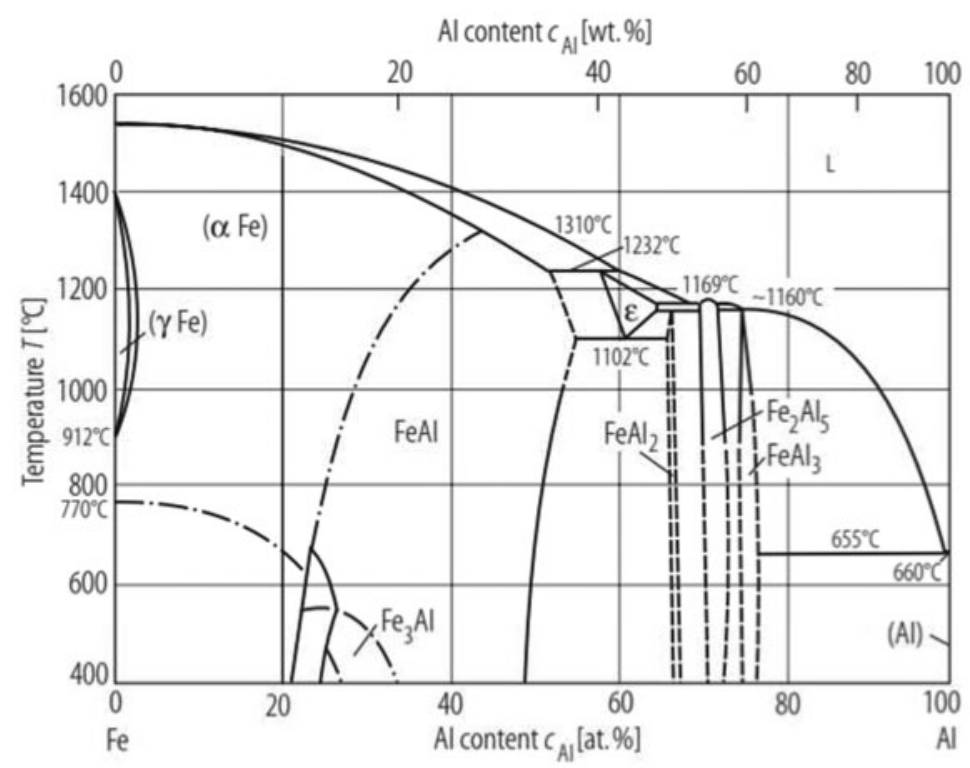

11 Fe-Al phase diagram ${ }^{23}$

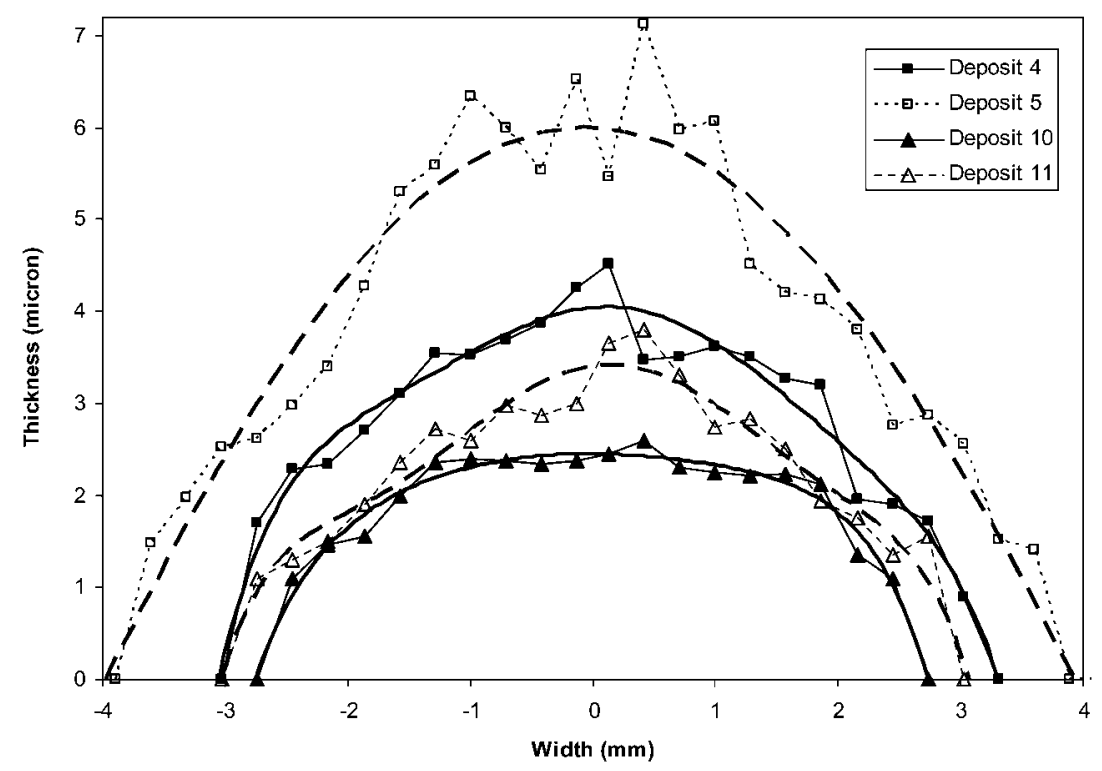

12 comparison of intermetallic thickness distribution for various tests

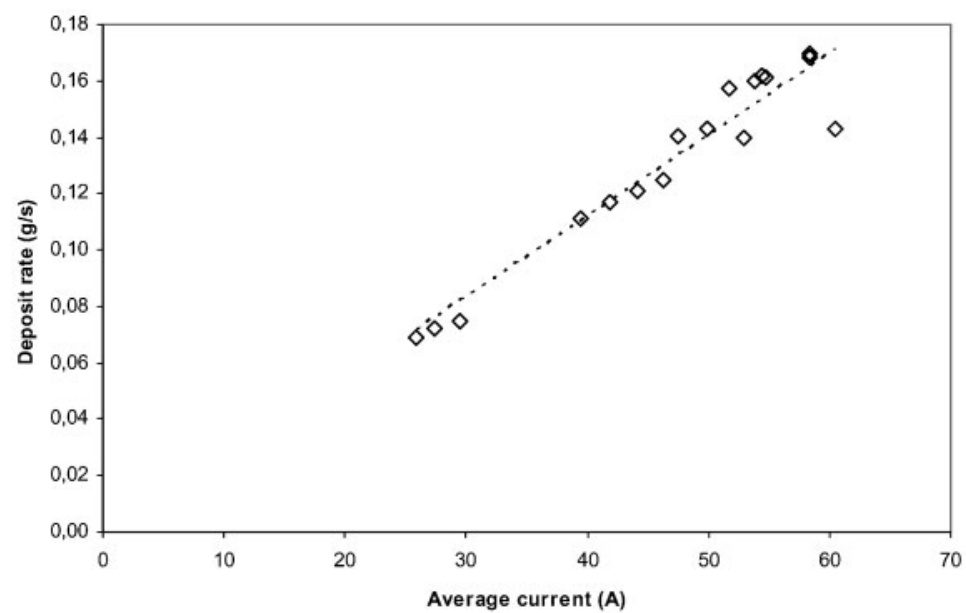

13 evolution of the deposit rate versus the mean current 


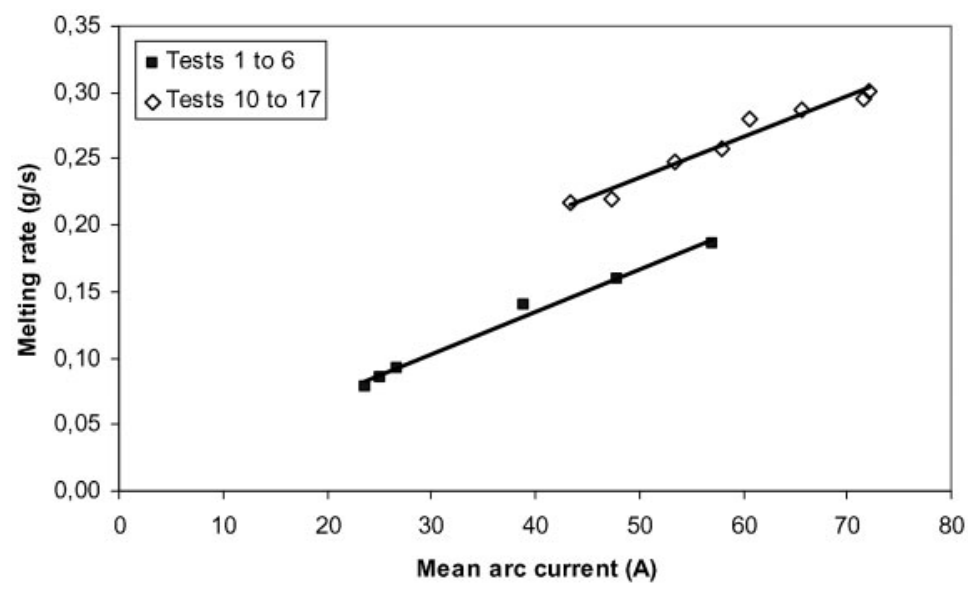

14 evolution of the melting rate versus the mean arc current considering only the arcing phase

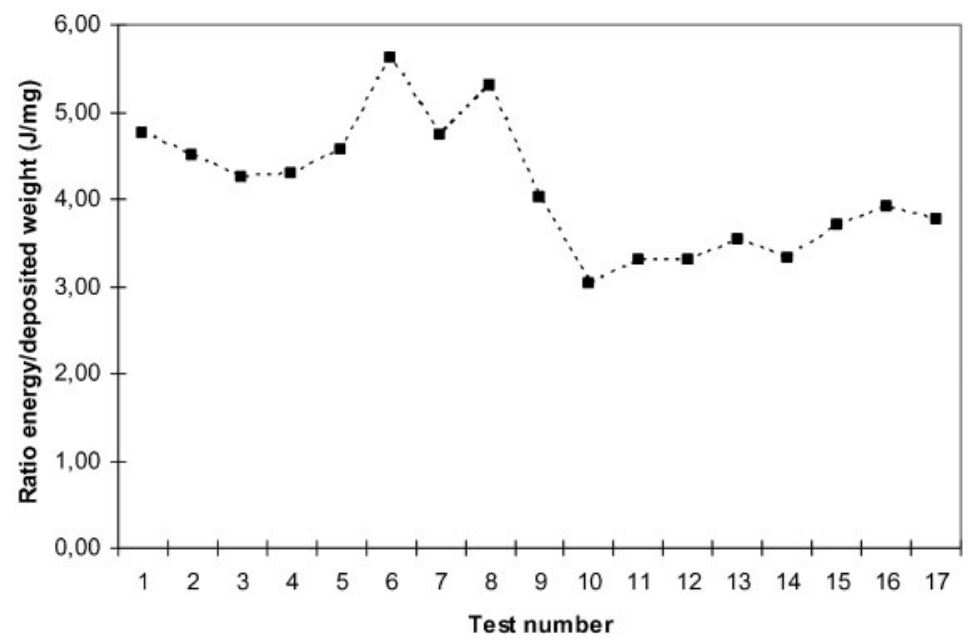

15 ratio between the welding energy and the deposited weight for the various tests

to the waveform, as suggests the variation of energy for a similar deposit rate when the short-circuit frequency increases (Figs. 5-6).

Figure 14 represents the relation between the mean current during the arcing phase and the melting rate (considering the melting of the wire tip occurs only during the arcing phase). One can observe for an equivalent mean current of arcing phase, that the melting rate is higher for the last tests, where the short-circuit frequency is high, than for the first ones.

The heat transferred to the base metal during the short circuit phase mainly depends on the short-circuit duration, and on the heat contained in the wire tip, which is related to its temperature and to the volume of heated filler metal. In the various tests performed in this study, the short-circuit time is about the same, so the heat transferred to the base metal depends on the last factor. For tests from $\mathrm{n}^{\circ} 10$, the arcing time is short ( $\sim 6 \mathrm{~ms})$, and the mass of the formed drops is rather low. In contrast, for the first welding tests, the arcing time is longer than the short-circuit duration, and the drops mass is higher, indicating a higher global heat contained in the drop, and probably a higher mean temperature, as suggested by the higher ratio between energy and deposited weight for the first tests (Fig. 15). The heat transferred from the wire tip to the base metal should then be higher, despite of the lower short-circuit frequency compared to the last tests.

That explains the higher thickness of intermetallic layer formed during the first tests (Fig. 12), with a similar deposit rate. Indeed, in GMAW-DCEP, it is generally admitted that the heating of the base metal is mainly due to the heat transfer from the deposited filler metal. The heat transferred to the steel surface during the short-circuit phases, higher for the first waveform type, thus induces the formation and growth of a thicker intermetallic layer.

\section{Conclusions}

The CMT process allows to deposit regular aluminium welds on $\mathrm{Zn}$ coated steel sheets, except for high heat input, where the vapourisation of the $\mathrm{Zn}$ layer prevents the wetting of aluminium. The decrease in the 'boost' time coupled to the increase in the boost current of the CMT waveform produces an increase in the short-circuit frequency and a decrease in the drop weight deposited during each short-circuit. This kind of waveform produces the best results in steel-aluminium joining because the heat transferred to the base metal is reduced for an equivalent deposited weight, and the thickness of the formed Fe-Al intermetallic layer is lower. 


\section{Acknowledgements}

The authors gratefully acknowledge the programme Averroes 4 of Erasmus Mundus for its financial support of this work.

\section{References}

1. J. H. Han, J. P. Ahn and M. C. Shin: 'Effect of interlayer thickness on shear deformation behaviour of AA5083 aluminium alloy/SS41 steel plates manufactured by explosive welding', J. Mater. Sci., 2003, 38, 13-18.

2. S. Fukumoto, H. Tsubakino, K. Okita, M. Aritoshi and T. Tomita: 'Friction welding process of 5052 aluminium alloy to 304 stainless steel', Mater. Sci. Technol., 1999, 15, 1080-1086.

3. K. Kimapong and T. Watanabe: 'Friction stir welding of aluminium alloy to steel', Weld. J., 2004, 83, 277-282.

4. D. R. Andrews: 'Joining aluminium to mild steel by argon arc welding', Brit. Weld. J., 1962, 9, 650-658.

5. G. A. Bel'chuk: 'Investigation of certain features of the argon-arc welding of aluminium and its alloys to steel', Weld. Prod., 1961, 5, 14-20.

6. M. Yasuyama, K. Ogawa and T. Taka: 'Spot welding of aluminium and steel sheet with an insert of aluminium clad steel sheet: dissimilar metal joining of aluminium and steel sheet ( $1^{\text {st }}$ Report)', Weld. Int., 1996, 10, 965-970.

7. X. Sun, E. V. Stephens, M. A. Khaleel, H. Shao and M. Kimchi, 'Resistance spot-welding of aluminium alloy to steel with transition material - from process to performance - part I: experimental study' Weld. J., 2004, 83, 188s-195s.

8. M. Roulin, J. W. Luster, G. Karadeniz and A. Mortensen: 'Strength and structure of furnace-brazed joints between aluminium and stainless steel', Weld. J., 1999, 78, 151-155.

9. S. B. Lin, J. L. Song, C. L. Yang, C. L. Fan and D. W. Zhang: 'Brazability of dissimilar metals tungsten inert gas butt weldingbrazing between aluminum alloy and stainless steel with $\mathrm{Al}-\mathrm{Cu}$ filler metal', Mater. Des., 2010, 31, 2637-2642.

10. A. Mathieu, S. Pontevicci, J.-C. Viala, E. Cicala, S. Mattei and D. Grevey: 'Laser brazing of a steel/aluminium assembly with hot filler wire (88\% Al, 12\% Si)', Mater. Sci. Eng. A, 2006, 435-436, 19-28.

11. G. Sierra, P. Peyre, F. Deschaux-Beaume, D. Stuart and G. Fras: 'Steel to aluminium key-hole laser welding', Mater. Sci. Eng. A, 2007, 447, 197-208.
12. G. Sierra, P. Peyre, F. Deschaux Beaume, D. Stuart and G. Fras: 'Galvanised steel to aluminium joining by laser and GTAW processes', Mater. Charact., 2008, 59, 1705-1715.

13. P. Peyre, G. Sierra, F. Deschaux-Beaume, D. Stuart and G. Fras: 'Generation of aluminium-steel joints with laser-induced reactive wetting', Mater. Sci. Eng. A, 2007, 444, 327-338.

14. G. Sierra, P. Peyre, F. Deschaux Beaume, D. Stuart and G. Fras: 'Steel to aluminium braze-welding by laser process with an $\mathrm{Al}-12 \mathrm{Si}$ filler wire', Sci. Technol. Weld. Join., 2008, 13, 430-437.

15. Honggang Dong, Wenjin Hu, Yuping Duan, Xudong Wang and Chuang Dong: 'Dissimilar metal joining of aluminum alloy to galvanized steel with $\mathrm{Al}-\mathrm{Si}, \mathrm{Al}-\mathrm{Cu}, \mathrm{Al}-\mathrm{Si}-\mathrm{Cu}$ and $\mathrm{Zn}-\mathrm{Al}$ filler wires', J. Mater. Process. Technol., 2012, 212, 458-464.

16. J. C. Feng, H. T. Zhang and P. He: 'The CMT short-circuiting metal transfer process and its use in thin aluminium sheets welding', Mater. Des., 2009, 30, 1850-1852.

17. H. T. Zhang, J. C. Feng, P. He and H. Hackl: 'Interfacial microstructure and mechanical properties of aluminium-zinccoated steel joints made by a modified metal inert gas weldingbrazing process', Mater. Charact., 2007, 58, 588-592.

18. H. T. Zhang, J. C. Feng, P. He, B. B. Zhang, J. M. Chen and L. Wang: 'The arc characteristics and metal transfer behaviour of cold metal transfer and its use in joining aluminium to zinc-coated steel', Mater. Sci. Eng. A, 2009, 499, 111-113.

19. R. Cao, G. Yu, J. H. Chen and P. C. Wang: 'Cold metal transfer joining aluminum alloys to galvanized mild steel', J. Mater. Process. Technol., 2013, 213, 1753-1763.

20. R. Cao, Q. Huang, J. H. Chen and P. C. Wang: 'Cold meta transfer spot plug welding of AA6061-T6 to galvanized steel for automotive applications', J. Alloys Comp., 2014, 585, 622-632.

21. S. Yang, J. Zhang, J. Lian and Y. Lei: 'Welding of aluminum alloy to zinc coated steel by cold metal transfer', Mater. Des., 2013, 49, 602-612.

22. C. G. Pickin, S. W. Williams and M. Lunt: 'Characterisation of the cold metal transfer (CMT) process and its application for low dilution cladding', J. Mater. Process. Technol., 2011, 211, 496-502.

23. T. B. Massalski, J. L. Murray, L. H. Bennett and H. Baker: 'Binary Alloy Phase Diagrams' Vol. 1, 148; 1986, Metals Park, Ohio, American Society for Metals.

24. A. Lesnewich: 'Control of melting rate and metal transfer in gas shielded metal arc welding. Part I - Control of electrode melting rate', Weld. J., 1958, 37, 343s.

25. H. Waszink and J. P. M. Van Den Heuvel: 'Heat Generation and Heat Flow in the Filler Metal in GMA Welding', Weld. J., 1982, 61, 269-280. 